\section{KẾT LUẬN}

Đốt nhiệt sóng cao tần là phương pháp an toàn và hiệu quả trong điều nốt di căn phổi đường kính nhỏ hơn $3 \mathrm{~cm}$ với tỷ lệ loại bỏ hoàn toàn tổn thương cao và tỷ lệ biến chứng thấp.

\section{TÀI LIÊU THAM KHẢO}

1. Meybaum, C.; Graff, M.; Fallenberg, E. M.; Leschber, G.; Wormanns, D. Contribution of CAD to the Sensitivity for Detecting Lung Metastases on Thin-Section CT - A Prospective Study with Surgical and Histopathological Correlation. Rofo 2020, 192 (1), 65-73. https://doi.org/10.1055/a-0977-3453.

2. Tongdee, T.; Tantigate, P.; Tongdee, $\mathbf{R}$. Radiofrequency Ablation of Lung Metastasis Not Suitable for Surgery: Experience in Siriraj Hospital. J Med Assoc Thai 2015, 98 (10), 1019-1027.

3. Prud'homme, C.; Deschamps, F.; Moulin, B.; Hakime, A.; Al-Ahmar, M.; Moalla, S.; Roux, C.; Terititehau, C.; de Baere, T.; Tselikas, L. Image-Guided Lung Metastasis Ablation: A Literature Review. Int J Hyperthermia 2019, 36 (2), 37-45. https://doi.org/ 10.1080/ 02656736.2019 .1647358$.

4. Schneider, T.; Warth, A.; Herpel, E.; Schnabel,
P. A.; von Deimling, A.; Eberhardt, R.; Herth, F. J. F.; Dienemann, H.; Hoffmann, $H$. Intraoperative Radiofrequency Ablation of Lung Metastases and Histologic Evaluation. The Annals of Thoracic Surgery 2009, 87 (2), 379-384. https://doi.org/10.1016/j.athoracsur.2008.10.088.

5. Chua, T. C.; Sarkar, A.; Saxena, A.; Glenn, D.; Zhao, J.; Morris, D. L. Long -Term Outcome of Image-Guided Percutaneous Radiofrequency Ablation of Lung Metastases: An Open-Labeled Prospective Trial of 148 Patients. Annals of Oncology 2010, 21 (10), 2017-2022. https://doi.org/10.1093/annonc/mdq098.

6. Baère, T. de; Aupérin, A.; Deschamps, F.; Chevallier, P.; Gaubert, Y.; Boige, V.; Fonck, M.; Escudier, B.; Palussiére, J. Radiofrequency Ablation Is a Valid Treatment Option for Lung Metastases: Experience in 566 Patients with 1037 Metastases. Annals of Oncology 2015, 26 (5), 987-991. https://doi.org/10.1093/annonc/mdv037.

7. Pfannschmidt, J.; Bischoff, M.; Muley, T.; Kunz, J.; Zamecnik, P.; Schnabel, P. A.; Hoffmann, H.; Dienemann, H.; Heussel, C. P. Diagnosis of Pulmonary Metastases with Helical CT: The Effect of Imaging Techniques. Thorac Cardiovasc Surg 2008, 56 (8), 471-475. https://doi.org/10.1055/s-2008-1038887.

\title{
ĐĂC ĐIỂM LÂM SÀNG, HÌNH ẢNH CộNG HƯởNG TỪ NÃO MẠCH NÃO VÀ BƯớC ĐÂUU ĐÁNH GIÁ HIỀU QUẢ CỦA RIVAROXABAN TRONG ĐIỀU TRI HUYẾT KHỐI TĨNH MACH NÃO
}

\author{
Phạm Thị Ngọc Linh ${ }^{1}$, Võ Hồng Khôi ${ }^{2}$, Nguyễn Ngọc Hòa ${ }^{3}$
}

\section{TÓM TẮT}

Muc tiêu: Mô tả đăc điểm lâm sàng, hình ảnh cộng hưởng từ não mạch não và bước đâuu đánh giá hiệu quả của Rivaroxaban trong điều trị huyết khối tĩnh mach não. Đối tượng và phương pháp: Nghiên cứu mổ tả tiến cứu được thực hiện trên 38 bệnh nhân huyết khối tĩnh mach não điều tri tai Khoa Thần Kinh, Bệnh viện Bạch Mai từ tháng 3 nằm 2020 đến tháng 6 nắm 2021. Kết quả: Tuổi trung bình của nhóm nghiên cứu là $42,4 \pm 14,8$. Tỷ lệ nam/nữ là 1,2 . Thời gian khởi phát: cấp tính có 6 bênh nhân $(15,8 \%)$, bán cấp có 31 bệnh nhân $(81,6 \%)$, mạn tính có 1 bệnh nhân $(2,6 \%)$. Triệu chứng thường gặp nhất là đau đầu $(94,7 \%)$, tiếp theo là liệt nửa người $(34,2 \%)$ và co giât $(28,9 \%)$. Trên phim công hưởng từ não mach não,tổn thương hay gặp nhất là nhồi máu não $(31,6 \%)$, chảy máu não $(21,1 \%)$ và nhồi máu não

${ }^{1}$ Trường Đại học Y Hà Nội

${ }^{2}$ Bênh viên Bach Mai

${ }^{3}$ Bềnh viền Hưư nghi Đa khoa Nghê An.

Chịu trách nhiêm chính: Phạm Thị Ngọc Linh

Email: Ngoclinhpham181295@gmail.com

Ngày nhận bài: 17.6.2021

Ngày phản biên khoa họ: 16.8.2021

Ngày duyệt bài: 23.8.2021 chuyển dang chảy máu $(18,4 \%)$. Vị trí huyết khối thướng gắp nhất là xoang dọc trên $(73,7 \%)$, xoang ngang $(63,2 \%)$ và xoang sigma $(47,4 \%)$. Bước đầu đánh giá hiêu quả của Rivaroxaban trong điều tri huyết khối tĩnh mạch não sau 12 tuân theo dõi điêu trị khá khả quan. Tỷ lệ bênh nhân hồi phuc tốt có điểm mRS từ 0-1 điểm 94,7\%. Tỷ lệ tái phát các sự kiện huyết khối tĩnh mach thấp 2,6\%.

Từ khoá: Huyết khối tĩnh mạch não, rivaroxaban.

\section{SUMMARY}

\section{CLINICAL FEATURES CLINICAL FEATURES MAGNETIC RESONANCE IMAGING AND INITIAL \\ EVALUATION OF THE EFFECTIVENESS OF RIVAROXABAN IN THE TREATMENT OF CEREBRAL VENOUSTHROMBOSIS}

Objective:To describe clinical features, magnetic resonance imaging and initial evaluate the effectiveness of rivaroxaban in the treatment of cerebral venous thrombosis. Subjects and methods: A prospective, descriptive study of 38 patients with cerebral venous thrombosistreated at the Department of Neurology, Bach Mai Hospital from March 2020 to June 2021. Results: Mean age was $42.4 \pm 14.8$, male/female ratio was 1.2:1. Acute onset was seen in 6 patients $(15.8 \%)$, subacute in $31(81.6 \%)$ and 
chronic in $1(2.6 \%)$. Most cases onset frequently with headache $(94.7 \%)$, followed by hemiparesis $(34.2 \%)$ and seizure (28.9\%). 25 patients $(65.8 \%)$ had parenchymal brain lesions in MRI, including venous infarct $(31.6 \%)$, hemorrhage $(21.1 \%)$, hemorrhagic infarct $(18.4 \%)$. Involvement of the superior sagittal sinus was found in $73.7 \%$ patients, the transverse sinus in $63.2 \%$ patients and sigma sinus $47.4 \%$ patients. The initial evaluation of the effectiveness of rivaroxaban in the treatment of cerebral venous thrombosis is quite promising. $94.7 \%$ of patients had good recovery with mRS score from 0-1 point. The recurrence rate was low, with $2.6 \%$ of venous thromboembolic events recurred.

Keywords: Cerebral venous thrombosis, rivaroxaban.

\section{I. ĐẶT VẤN ĐỀ}

Huyết khối tĩnh mạch não (HKTMN) là thuật ngữ chung mô tả bệnh lý huyết khối của hệ thống tĩnh mạch não bao gồm huyết khối xoang tĩnh mạch màng cứng và hệ thống tĩnh mạch não sâu cũng như tĩnh mạch vùng vỏ não. Đây là một thể ít gặp trong số các bệnh lý đột quy. (chiếm 0,5-1\% số bệnh nhân đột quy) với tỷ lệ mới mắc bệnh $5 / 1000000$ dân môi năm[1]. Những bệnh nhân mắc huyết khối tĩnh mạch não này sau khi trải qua giai đoạn cấp thì có nguy cơ bị tái phát các sự kiện huyết khối tĩnh mạch (VTEs). Thuốc chổng đông đường uống thế hệ mới NOAC đã và đang làm thay đổi thái độ điều trị về việc sử dụng thuốc chống đông trong điêu trị dự phòng các sự kiện huyết khối tĩnh mạch sau khi mắc huyết khối tĩnh mạch não.

Rivaroxaban là thuốc chống đông đường uống thế hệ mới (NOAC) nhóm ức chế trực tiếp yếu tố $X a$. Nhiều nghiên cứu trên thế giới đã chứng minh được tính an toàn và hiệu quả của NOAC nói chung và Rivaroxaban nói riêng trong điều trị huyết khối tĩnh mạch não, tuy nhiên ở Viêt Nam hiện nay chưa có nghiên cứu nào về vấn đề này. Vì vậy, chúng tôi tiến hành nghiên cứu: "Đặc điểm lâmm sàng, hình ảnh cộng hưởng từ não mạch não và bước đầu đánh giá hiệu quả của rivaroxaban trong điều trị huyết khối tînh mạch não" với hai muc tiêu sau:

1. Mô tả đặc điểm lâm sàng, hình ảnh công hưởng từ não mạch não ở bệnh nhân huyêt khối tĩnh mạch não.

2. Nhận xét tính an toàn và hiệu quả của Rivaroxaban trong điều trị huyêt khôi tĩnh mạch não.

\section{II. ĐỐI TƯợNG VÀ PHƯƠNG PHÁP NGHIÊN CỨU}

2.1. Đối tượng nghiên cứu. Đối tượng nghiên cứu gồm 38 bệnh nhân được chẩn đoán xác định huyết khối tĩnh mạch não điều trị tại khoa Thần kinh, Bệnh viện Bạch Mai từ tháng 03/2020 đến tháng 06/2021.

\subsubsection{Tiêu chuẩn lựa chọn đối tượng} tham gia nghiên cứu:

+ Tuổi $\geq 18$ tuổi.

+ Chẩn đoán xác định huyết khối tĩnh mạch não bằng chụp cộng hưởng từ não mạch não 1,5 Tesla tại Bệnh viện Bạch Mai, điều trị giai đoạn cấp ổn định bằng thuốc chống đông heparin trọng lượng phân tử thấp 5-15 ngày.

+ Đủ điều kiện sử dụng thuốc chống đông đường uống để điều trị huyết khối tĩnh mạch não, dựa trên đánh giá của điều tra viên về nguy cơ và tình trạng lâm sàng.

\subsubsection{Tiêu chuẩn loại trừ}

+ Huyết khối tĩnh mạch não liên quan với nhiễm trùng hệ thần kinh trung ương, chấn thương đâu.

+ Bệnh nhân đang có tình trạng nguy cơ chảy máu cao.

+ Suy gan nặng, suy thận nặng.

2.2. Phương pháp nghiên cứu

2.2.1. Thiết kế nghiên cứu: Nghiên cứu mô tả tiến cứu.

2.2.2. Phương pháp chọn mẫu: Chọn mẫu thuận tiên.

2.2.3. Phương pháp thống kê và xử lý số liệu: Theo chương trình SPSS 20.

\section{KẾT QUẢ NGHIÊN CứU}

3.1. Đặc điểm chung của đối tượng nghiên cứu

Bảng 1: Đặc điểm chung của đổi tượng nghiên cứu

\begin{tabular}{|c|c|c|c|c|}
\hline \multirow{2}{*}{ Tuổi- giới tính } & Nam & Nữ & Chung \\
\cline { 2 - 5 } & Tuối trung bình & $\mathbf{n = 2 1 ( 5 3 , 3 \% )}$ & $\mathbf{n = 1 7 ( 4 4 , 7 \% )}$ & $\mathbf{n = 3 8 ( 1 0 0 \% )}$ \\
\hline \multirow{4}{*}{$\begin{array}{c}\text { Phân bố } \\
\text { theo } \\
\text { nhóm } \\
\text { tuối }\end{array}$} & (khoảng tuối) & $(19-77$ tuối) & $36,0 \pm 10,1$ & $42,4 \pm 14,8$ \\
\cline { 2 - 5 } & $\leq 20$ tuối & $2(9,5)$ & $0(0)$ & $(19-77$ tuối) \\
\cline { 2 - 5 } & $21-30$ tuối & $1(4,8)$ & $6(35,3)$ & $2(5,3)$ \\
\cline { 2 - 5 } & $31-40$ tuối & $4(19,0)$ & $4(23,5)$ & $8(21,1)$ \\
\cline { 2 - 5 } & $41-50$ tuối & $2(9,5)$ & $6(35,3)$ & $8(21,1)$ \\
\cline { 2 - 5 } & $51-60$ tuối & $7(33,3)$ & $1(5,9)$ & $4(10,5)$ \\
\cline { 2 - 5 } & 61-70 tuối & $4(19,0)$ & $0(0)$ & $1(2,6)$ \\
\hline
\end{tabular}


Nhận xét: Nghiên cứu được thực hiên trên 38 bệnh nhân. Tuổi trung bình là $42,4 \pm 14,8$, tuổi nhỏ nhất là 19 và lớn nhất là 77 . Tuổi trung bình mắc ở nam là $47,1 \pm 16,1$ cao hơn tuổi trung bình mắc ở nữ $36,0 \pm 10,1$.Tỷ lệ mắc ở nam và nữ là tương đương nhau với tỷ lệ nam/nữ là 1,2 .

3.2. Đặc điểm lâm sàng và hình ảnh học não xoang tĩnh mạch não của đối tượng nghiên cứu

3.2.1. Đặc điểm khởi phát triệu chứng lâm sàng

Bảng 2: Đặc điểm khởi phát bệnh

\begin{tabular}{|c|c|c|}
\hline Khởi phát & $\begin{array}{c}\text { Số bệnh } \\
\text { nhẩn } \\
\text { (n=38) }\end{array}$ & $\begin{array}{c}\text { Tỷ lề } \\
\mathbf{( \% )}\end{array}$ \\
\hline Cấp tính ( $\leq 2$ ngày) & 6 & 15,8 \\
\hline Bán cấp (>2ngày-30ngày) & 31 & 81,6 \\
\hline Mạn tính (>30 ngày) & 1 & 2,6 \\
\hline Tống số & $\mathbf{3 8}$ & $\mathbf{1 0 0}$ \\
\hline
\end{tabular}

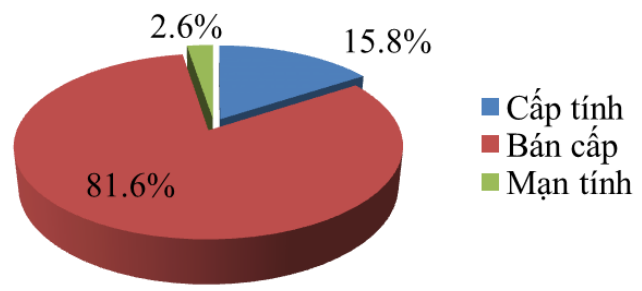

Nhận xét: Kết quả bảng trên cho thấy đặc điểm khởi phát của bệnh rất đa dạng. Đa sỗ bệnh nhân $(81,6 \%)$ có khởi phát bệnh bán cấp, khới phát cấp tính giống đột quy động mạch ít gặp hơn chiếm 15,8\%. It gặp nhất là khởi phát mạn tính, chỉ gặp ở 2,6\% số bệnh nhân.

\subsubsection{Triệu chứng khởi phát bệnh}

Bảng 3: Triệu chứng khởi phát bệnh

\begin{tabular}{|c|c|c|}
\hline Triệu chứng & $\mathbf{n = 3 8}$ & Tỷ lệ (\%) \\
\hline Đau đâu & 36 & 94,7 \\
\hline Liệt nửa người & 13 & 34,2 \\
\hline Co giật & 11 & 28,9 \\
\hline Rối loạn ỳ thức & 6 & 15,8 \\
\hline
\end{tabular}

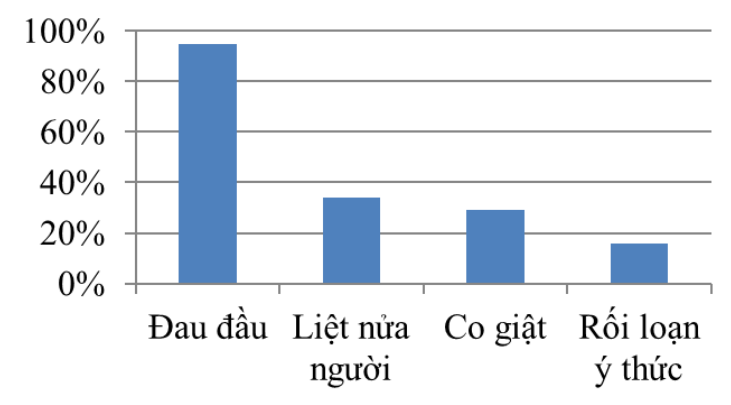

Nhận xét: Trong số các triệu chứng khởi phát, đau đầu là triệu chứng khởi phát thường gặp nhất chiếm tỷ lệ 94,7\%. Triệu chứng liệt nửa người cũng thường gặp chiếm tỷ lệ 34,2\%. Triệu chứng co giật gặp với tỷ lệ ít hơn chiếm 28,9\% và triệu chứng khởi phát ít gặp nhất là rối loạn ý thức, chỉ gặp ở 15,8\% số bệnh nhân.

3.2.3. Đặc điểm hình ảnh chụp cộng hưởng từ não

Bảng 4: Hình ảnh chupp công hưởng từ não

\begin{tabular}{|c|c|c|}
\hline Hình ảnh MRI não & $\mathbf{n = 3 8}$ & $\begin{array}{c}\text { Tỷ lệ } \\
(\mathbf{\%})\end{array}$ \\
\hline Nhồi máu não & 12 & 31,6 \\
\hline Chày máu não & 8 & 21,1 \\
\hline Nhồi máu chảy máu não & 7 & 18,4 \\
\hline Nhu mô não bình thường & 10 & 26,3 \\
\hline Chảy máu dưới nhện & 3 & 7,9 \\
\hline
\end{tabular}

Nhân xét: Trong số các tổn thương nhu mô não nhồi máu não gặp nhiều nhất chiếm tỉ lệ $31,6 \%$, ít gặ nhất là chảy máu dưới nhện chiếm $7,9 \%$. Trong số 38 bệnh nhân có 10 bệnh nhân không có tổn thương nhu mô não trên phim chụp cộng hưởng từ chiếm tỷ lệ $26,3 \%$. Các tổn thương não dang chảy máu não, nhồi máu não chuyển dạng chảy máu gặp với tỉ lệ ít hơn lần lượt là $21,1 \%$ và $18,4 \%$.

3.2.4. Đặc điểm hình ảnh chụp cộng hưởng từ xoang tĩnh mạch não

Bảng 5: Hình ảnh chụp cộng hưởng từ xoang tĩnh mạch não

\begin{tabular}{|c|c|c|}
\hline Xoang có huyết khối & $\mathbf{n = 3 8}$ & $\begin{array}{c}\text { Tỷ lệ } \\
(\mathbf{\%})\end{array}$ \\
\hline Xoang dọc trên & 28 & 73,7 \\
\hline Xoang ngang & 24 & 63,2 \\
\hline Xoang sigma & 18 & 47,4 \\
\hline Tînh mạch vỏ não & 9 & 23,7 \\
\hline Tĩnh mạch cảnh trong & 6 & 15,8 \\
\hline Xoang thắng & 3 & 7,9 \\
\hline Xoang dọc dưới & 3 & 7,9 \\
\hline Tînh mạch não sâu & 1 & 2,6 \\
\hline Tắc một xoang & 11 & 28,9 \\
\hline Tắc nhiều xoang & 27 & 71,1 \\
\hline
\end{tabular}

Nhận xét: Vị trí huyết khối tĩnh mạch não thường gặp ở các xoang lớn, trong đó huyết khối xoang dọc trên thường gặp nhất chiếm tỷ lê $73,7 \%$, tiếp theo đó là xoang ngang chiếm tỷ lệ $63,2 \%$ và xoang sigma chiếm tỷ lệ $47,4 \%$. Trong số 38 bệnh nhân có tới 27 bệnh nhân tắc nhiều xoang tĩnh mạch đồng thời chiếm tỷ lệ $71,1 \%$.

3.3. Bước đâu đánh giá hiệu quả của Rivaroxaban trong điêu trị huyết khối tĩnh mạch não

3.3.1. Đánh giá mức độ hồi phục sau 12 tuần sử dụng Rívaroxaban

Bảng 6: Đánh giá mức độ hồi phục sau 
12 tuần

\begin{tabular}{|c|c|c|}
\hline Điếm mRS & Số lượng & Tỷ lệ (\%) \\
\hline $0-1$ & 36 & 94,7 \\
\hline 2 & 2 & 5,3 \\
\hline 3 & 0 & 0 \\
\hline$>3$ & 0 & 0 \\
\hline
\end{tabular}

Nhận xét: Sau 12 tuần sử dụng Rivaroxaban, đa số các bệnh nhân có sự hồi phục tốt mRS lí tưởng từ $0-1$ điểm chiếm tỷ lệ cao tới 94,7\%. Trong số 38 bệnh nhân nghiên cứu có 2 bệnh nhân còn di chứng mất chức năng nhẹ chiếm tỷ lệ $5,3 \%$. Không có bệnh nhân nào di chứng mất chức năng từ trung bình đến nặng $\mathrm{mRS} \geq 3$ điểm.

3.3.2. Các sự kiện tái phát huyêt khôii tĩnh mạch và chảy máu lớn sau 12 tuần dùng Rivaroxaban

Bảng 7: Tái phát biến cố huyết khôi tĩnh mach sau 12 tuần

\begin{tabular}{|c|c|c|}
\hline Loại biến cố & Số lượng & Tỷ lệ (\%) \\
\hline $\begin{array}{c}\text { Huyết khối tĩnh } \\
\text { mạch não tái phát }\end{array}$ & 0 & 0 \\
\hline $\begin{array}{c}\text { Huyết khối tînh } \\
\text { mạch chi }\end{array}$ & 1 & 2,6 \\
\hline $\begin{array}{c}\text { Huyết khối tĩnh } \\
\text { mạch tạng }\end{array}$ & 0 & 0 \\
\hline Tắc mạch phối & 0 & 0 \\
\hline
\end{tabular}

Nhận xét: Sau 12 tuần sử dụng Rivaroxaban, có 1 trường hợp tái phát huyết khối tĩnh mạch chi dưới chiếm tỷ lệ $2,6 \%$, chưa ghi nhận trường hợp bệnh nhân nào tái phát huyết khối tĩnh mạch não huyết khối tĩnh mạch tạng và tắc mạch phổi. Trong số 38 bệnh nhẩn chưa ghi nhận biến cố chảy máu lớn nào sau 12 tuần sử dụng Rivaroxaban.

\section{BÀN LUÂN}

Nghiên cứu được tiến hành trên 38 bệnh nhân được chẩn đoán huyết khối tĩnh mạch não điều trị ổn định giai đoạn cấp bằng Heparin trọng lượng phân tử thấp từ 5-15 ngày, sau đó duy trì điều trị bằng Rivaroxaban $20 \mathrm{mg} / \mathrm{ngày}$ theo dõi và đánh giá sau 12 tuần điều trị. Kết quả của chúng tôi cho thấy nhóm tuổi trung bình của nhóm nghiên cứu là $42,4 \pm 14,8$ tuối (dao động từ 19-77 tuổi). So với nam giới, thì nữ giới có độ tuổi mắc trẻ hơn (tuổi trung bình ở nhóm nữ là $36,0 \pm 10,1$ tuổiso với trung bình ở nhóm nam là $47,1 \pm 16,1$ tuổi). Kết quả này cũng phù hợp với nghiên cứu của Coutinho JM và cộng sự [2]. Tỷ lệ mắc ở nam và nữ là tương đương nhau với tỷ lệ nam/nữ là 1,2 . Kết quả này tương đương với một số nghiên cứu trong và ngoài nước [2][3][4]. Tỷ lệ bệnh nhân huyết khối tĩnh mạch não gặp nhiều nhất ở lứa tuổi trẻ, đây thường là lứa tuổi liên quan đến sinh đẻ và thai sản cũng như có các bất thường về di truyền gây tác động lên các yếu tố đông máu, dẫn đến nguy cơ hình thành huyết khối. Đặc điểm lâm sàng và triệu chứng khởi phát của bệnh rất đa dạng, đa số bệnh nhân $(81,6 \%)$ có khởi phát bệnh bán cấp, khởi phát cấp tính giống đột quỵ động mạch ít gặp hơn chỉ chiếm 15,8\%, ít gặp nhất là khởi phát mạn tính, chỉ gặp ở 2,6\% số bệnh nhân. Kết quả này phù hợp với nghiên cứu của Lê Văn Minh nhóm bệnh nhân khởi phát bán cấp cũng chiếm tỉ lệ cao nhất với 79,1\% [5]. Đau đầu là triệu chứng khởi phát thường gặp nhất chiếm tỷ lệ $94,7 \%$ phù hợp với nghiên cứu của Ferro JM và cộng sự [6], sau đó là liệt nửa người $34,2 \%$, co giật $28,9 \%$ và rối loạn ý thức $15,8 \%$.

Trong nghiên cứu của chúng tôi tổn thương nhu mô não thường gặp nhất trên cộng hưởng từ là nhồi máu não chiếm tỷ lệ $31,6 \%$, tiếp theo đó là chảy máu não và nhồi máu não chuyển dạng chảy máu lần lượt chiếm tỷ lệ $21,1 \%$ và $18,4 \%$. Tỷ lệ không gặp tổn thương nhu mô não cũng thường gặp chiếm $26,3 \%$ và chảy máu dưới nhện ít gặp nhất chiếm $7,9 \%$. Kết quả này cũng phù hợpvới nghiên cứu quốc tế trên 624 bệnh nhân của Ferro JM và cộng sự tổn thương nhồi máu não thường gặp nhất chiếm $46,5 \%$ và chảy máu não 39,3\% [6]. Kết quả nghiên cứu của chúng tôi và các tác giả trên thế giới thấy tỷ lệ bệnh nhân huyết khối tĩnh mạch não có tồn thương nhu mô não tương đối cao, các dang tổn thương nhu mô não đều có thể gặp trong đó thường gặp nhất là nhồi máu não. Trên hình ảnh chụp cộng hưởng từ xoang tĩnh mạch não, vị trí huyết khối thường gặp ở những xoang lớn, trong đó hay gặp nhất là xoang dọc trên chiếm $73,7 \%$, tiếp đến là xoang ngang chiếm $63,2 \%$ và xoang sigma chiếm $47,4 \%$. Đa số các trường hợp huyết khối tĩnh mạch não xảy ra ở nhiều xoang đồng thời chiếm tới $71,1 \%$, ít khi gặp đơn độc 1 xoang. Kết quả này phù hợp với nghiên cứu của tác giả Trịnh Tiến Lực [4].

Trong nghiên cứu của chúng tôi 38 bệnh nhân được sử dụng Rivaroxaban liều $20 \mathrm{mg} / \mathrm{ngày}$ đánh giá và theo dõi trong suốt 12 tuần. Tại thời điểm 12 tuần đa số các bệnh nhân có sự hồi phục tốt $\mathrm{mRS}$ lí tưởng từ $0-1$ điểm chiếm tỷ lệ cao tới $94,7 \%$, có 2 bệnh nhân còn di chứng mất chức năng nhe chiếm tỷ lệ 5,3\%, không có bệnh nhân nào di chứng mất chức năng từ trung bình đến nă̆ng $m R S \geq 3$ điểm. Trong suốt 12 tuần theo dõi có 1 trường hợp tái phát huyết khối tĩnh mạch chi dưới chiếm tỷ lệ 2,6\%, chưa ghi nhận 
trường hợp bệnh nhân nào tái phát huyết khối tĩnh mạch não, huyết khối tĩnh mạch tạng và tắc mạch phổi. Trong số 38 bệnh nhân cũng chưa quan sát được biến cố chảy máu lớn nào sau 12 tuần sử dung Rivaroxaban. Tác giả Ferro JM và cộng sự cũng quan sát được trong nghiên cứu của mình trên bệnh nhân huyết khối tĩnh mạch não, tỉ lệ hồi phục tốt mRS lí tưởng từ 0-1 điểm trong nhóm dùng thuốc chống đông thế hê mới sau 24 tuần là $91,5 \%$ và tỷ lệ chảy máu lớn thấp $1,7 \%[6]$.

\section{KẾT LUÂNN VÀ KHUYẾN NGH!}

Nghiên cứu trên 38 bệnh nhân huyết khối tĩnh mạch não điều trị giai đoạn cấp với Heparin trọng lượng phân tử thấp sau đó duy trì Rivaroxaban $20 \mathrm{mg} / \mathrm{ngày}$ trong 12 tuần, chúng tôi nhận thấy: Tuổi trung bình của nhóm nghiên cứu là 42,4 $\pm 14,8$ tuổi, nữ có độ tuổi mắc trẻ hơn nam và tỉ lệ nam/ nữ là 1,2 . Khởi phát bệnh có thể cấp tính, bán cấp hoặc mạn tính trong đó khởi phát bán cấp thường gặp nhất chiếm $79,1 \%$. Triệu chứng lâm sàng của bệnh rất đa dạng và không đặc hiệu, nhiều nhất là đau đâuu chiếm 94,7\%. Tổn thương nhồi máu não chiếm $31,6 \%$, chảy máu não $21,1 \%$ và nhồi máu não chuyển dạng chảy máu $18,4 \%$. Vị trí huyết khối thường gặp ở những xoang lớn, trong đó hay gặp nhất là xoang dọc trên $73,7 \%$, xoang ngang $63,2 \%$ và xoang sigma $47,4 \%$. Đa số huyết khối ở nhiều xoang đồng thời chiếm tới $71,1 \%$, ít khi gặp đơn độc 1 xoang.

Bước đầu đánh giá hiệu quả của Rivaroxaban trong điều trị huyết khối tĩnh mạch não sau 12 tuần theo dõi điều trị khá khả quan. Tỷ lê bênh nhân hồi phuc tốt có điểm mRS từ 0-1 điểm sau 12 tuần chiếm 94,7\%. Tỷ lệ tái phát các sự kiện huyết khối tĩnh mạch thấp 2,6\%.

\section{TÀI LIÊU THAM KHẢO}

1. Gustavo Saposnik, Fernando Barinagarrementeria, Robert D Brown Jr, et al. (2011). Diagnosis and management of cerebral venous thrombosis: a statement for healthcare professionals from the American Heart Association/American Stroke Association. Stroke, 42 (4), 1158-1192.

2. Jonathan $M$ Coutinho, José M Ferro, Patrícia Canhao, et al. (2009). Cerebral venous and sinus thrombosis in women. Stroke, 40 (7), 2356-2361.

3. Lê Văn Thính, Trịnh Tiến Lực (2010). Nhân xét một số đặc điểm lâm sàng, cận lâm sàng và điêu trị huyết khối tĩnh mạch não. Tập san Hội Thần kinh hoc Viêt Nam, 2, 10.

4. Trịnh Tiến Lực (2020). Nghiên cứu đặc điểm lâm sàng và hình ảnh học của bệnh nhân huyết khối tĩnh mach não Luân án Tiến sỹ y hoc, Đai hoc Y Hà Nội.

5. Lê Văn Minh. (2014), Nghiên cứu đặc điểm lâm sàng, hình ảnh não, một số yếu tố ngưy cơ và giá trị cúa D-Dimer trong chẩn đoán huyết khối tính mach não, Luân án Tiển sỹ Y hoc, Học viện Quân Y.

6. José M Ferro, Jonathan $M$ Coutinho, Francesco Dentali, et al. (2019). Safety and efficacy of dabigatran etexilate vs dose-adjusted warfarin in patients with cerebral venous thrombosis: a randomized clinical trial. JAMA neurology, 76 (12), 1457-1465.

\section{NGHIÊN CỨU VAI TRÒ TIÊN LƯỢNG CỦA GIÁ TRI HẤP THU CHUẨN 18F-FDG PET/CT Ở BÊNNH NHÂN UNG THƯ BIỂU MÔ VẢY THỰC QUẢN ĐIỀU TRI HOÁ - XẠ TRIỆT CĂN}

\section{TÓM TẮT}

Mục tiêu: Xác định vai trò các giá trị hấp thu chuẩn của ${ }^{18} \mathrm{~F}-\mathrm{FDG}$ PET/CT trước điều trị trong tiên lượng kết quả hóa - xạ triệt căn ở bệnh nhân ung thư biểu mô vảy thực quản. Đối tượng và phương pháp: Nghiên cứu can thiệp, tiến cứu trên 60 bệnh nhân ung thư biểu mô vảy thực quản $1 / 3$ trên được chụp ${ }^{18}$ F-FDG PET/CT đánh giá giai đoạn trước điêuu trị và chỉ định hoá xạ trị triệt căn. Các giá trị hấp thu

*Bênh viên Trung ương Quân đọi 108

Chịu trách nhiệm chính: Nguyễn Đình Châu

Email: chaunm108@gmail.com

Ngày nhận bài: 18.6.2021

Ngày phản biên khoa hoc: 13.8.2021

Ngày duyệt bài: 20.8.2021

\section{Nguyễn Đình Châu*, Lê Ngọc Hà ${ }^{2}$}

chuẩn ${ }^{18}$ F-FDG của khối $u$ bao gồm SUVmax, SUVmean, SUVpeak. Sử dụng đường cong ROC đế đánh giá ngưỡng SUV tối ưu liên quan tới đáp ứng và sống thêm. Phân tích đường cong Kaplan-Meier để ước tính sống thêm toàn bộ và sống thêm bệnh không tiến triển. Phân tích hồi quy Cox để tìm biến tiên lượng độc lâp với sống thêm. Kết quả: BN có đáp ứng hoàn toàn chiếm $38,3 \%$. Tỷ lệ sống thêm toàn bộ và sống thêm bênh không tiến triển 4 năm lần lượt là $48,6 \%$ và $44,4 \%$. SUVmean u tại ngưỡng 6,1 có giá trị dự báo đáp ứng hoàn toàn với đô nhay $69,6 \%$, độ đăc hiệu 78,4\%, độ chính xác 75\%. SUVmean u > 6,1 là yếu tố tiên lượng độc lập không thuận lợi cho sống thêm toàn bộ ( $H R=6,74, p=0,02)$ và sống thêm bệnh không tiến triển $(H R=6,53, p=0,00)$. Kết luận: Thông số SUVmean của u nguyên phát trên ${ }^{18} \mathrm{~F}-$ FDG PET/CT trước điều trị có thể sử dụng để tiên 